\title{
Body Mass Index of Healthy Nigerian Children
}

\author{
Anyiam J O, Ogala W N, Onuora C U \\ Department of Paediatrics, Ahmadu Bello University Teaching Hospital, Zaria
}

\begin{abstract}
Background: To study the Body Mass Index of healthy Nigerian school children from different socio-economic backgrounds resident in Kaduna, northern Nigeria.

Method: A cross-sectional prospective study of Body Mass Index was carried out on 3,802 healthy Nigerian school children aged 5 to 13 years resident in Kaduna, northern Nigeria. The subjects consist of 1,871 children from private schools (privileged) and 1,931 children from public schools (less privileged). The schools and pupils were selected by multi-staged cluster sampling method.
\end{abstract}

Result: Over 75\% of the 'privileged' and the 'less privileged' children are from upper and lower socioeconomic classes respectively. The mean Body Mass Index of the 'privileged' boys was $15.1 \pm 0.7$ compared with $14.7 \pm 1.2$ for the 'less privileged' boys. The corresponding mean Body Mass Index values for the 'privileged' and the 'less privileged' girls were $15.1 \pm 0.5$ and $15.0+1.7$ respectively. The difference in this index, between the boys as well as between the girls was statistically insignificant ( $p=0.05$ and 0.12 respectively).

Conclusion: There was no statistical significant difference between the BMI of the 'privileged' and the 'less privileged'groups of children.

\section{Date accepted for publication $12^{\text {th }}$ June 2008 Nig J Med 2008; 407 - 413 \\ Copyright $\odot 2008$ Nigerian Journal of Medicine}

Key Words- Body mass index, Children, Socio economic class, Nigeria

\section{Introduction}

Body mass index (BMI) also known as Quetelet's Index (Ql) is obtained by dividing the weight (in kilogrammes) by the square of the height (in metres). It is an important age independent anthropometric measurement used in the nutritional assessment of young children ${ }^{1}$. BMI takes in to consideration weight in relation to height and the BMI is considered to have advantages over using either height or weight singly as an index of growth. BMI is the preferred index in the assessment of body fatness among individual subjects ${ }^{2}$ and has a high correlation with skin fold measurements ${ }^{3}$, ${ }^{1}$. BMI in childhood changes substantially with age; at birth the median BMI is as low as $13 \mathrm{~kg} / \mathrm{m} 2$, increases to $17 \mathrm{~kg} / \mathrm{m} 2$ at age 1 , decreases to
$15.5 \mathrm{~kg} / \mathrm{m} 2$ at age 6 , then increases to $21 \mathrm{~kg} / \mathrm{m} 2$ at age 20.5

Over two decades ago BMI was studied in healthy children in northern Nigeria and southern India. ${ }^{6},{ }^{1}$ In eastern Nigeria, BMl of children with sickle cell disease aged $6-16$ years was studied in $1996^{7}$. The normal range for BMI stated by the authors in northern Nigeria ${ }^{6}$ was 15 -18. There was no difference in the BMl values of boys from both upper and lower socio-economic classes, but the girls from the lower class had higher values than their counterparts. ${ }^{6}$ BMl of sicklers was lower than controls matched for age and sex and there was no rise of BMI in male sicklers at puberty as was seen in the controls. ${ }^{7}$ The narrow range of BMl seen in the sicklers indicated the paucity of muscle mass as well as body fat. ${ }^{7}$ In south eastern Nigeria, a study on the profile of Body Mass Index and obesity in Nigerian children and adolescents reported the prevalence of obesity as $2.3 \%$ and $4.0 \%$ in children aged 6-12years old and adolescents of 1315years of age respectively. ${ }^{8}$ In southern India, BMI was the most useful index in early detection of protein calorie malnutrition in young children in that community ${ }^{1}$.In Brazil, ${ }^{9} \quad$ BMI varied by ethnicity with Mulattos but not Blacks, with both sexes having lower BMI than the Whites of the same age. Increasing secular trends in BMl of 6-year-old children from 1987 to 2002 was reported in Chile. ${ }^{10}$

The BMI has been recommended for use in adolescents screening programmed to select subjects with excess body fat for appropriate intervention. ${ }^{11,9}$ In northern Nigeria, the last study of BMI was over two decades ago ${ }^{6}$ and needs a review, hence this study.

The general aim of this study was therefore to study the Body Mass Index (BMI) of healthy school children in Kaduna, northern Nigeria from different socio-economic backgrounds and specifically to:

1. Calculate the BMI of the children in public ('less privileged') and private ('privileged') schools from their height and weight data.

2. compare the BMI of the children from public schools ('less privileged') with those from private schools ('privileged') given their different socio-economic backgrounds. 
3. relate the emergent baseline BMl data to data reported from a similar study in Nigeria, other countries and the International Standard.

4. compute BMI percentile data from the emergent data.

\section{Subjects and Methods}

This was a comparative cross-sectional prospective study conducted in primary school children in Kaduna in 1996. Kaduna is the capital of Kaduna state in northern Nigeria; with a 2002 projected population of $4,064872{ }^{12}$ The population is heterogenous. Many large industries and educational institutions (tertiary, post-primary and primary) are sited in this city. The occupations of the people were mainly civil service, teaching, trading, factory work and farming. Kaduna is located $150 \mathrm{~km}$ north of the federal capital city of Abuja. ${ }^{13}$ All the primary schools are co-educational. ${ }^{14}$ A study of $5 \%$ of the total number of 207 schools was undertaken because of cost and feasibility. The private schools cater mainly for the educational interest of privileged members of the society while the public schools cater for the educational interest of the less privileged .The age range of 5-13 years was selected because majority of primary school pupils are within this age range. The schools and pupils were selected by multistaged cluster sampling method. The schools were stratified into two groups: Private schools ('privileged') and Public schools ('less privileged') and selected separately. The minimum sample size (n) for this study was calculated for both groups separately using the formula, ${ }^{15,16}$ :

$$
C L=\frac{P-P 1}{\frac{\sigma}{v n}\left(v 1-\frac{n}{N}\right)}
$$

where $\mathrm{CL}=$ Confidence limit of $95 \%$

$\mathrm{P}-\mathrm{P} 1=$ Precision of $5 \%$

$\sigma=$ Standard deviation of mean weights for age from previous study.

$\mathrm{n}=$ minimum sample size.

$\mathrm{N}=$ Total population of pupils in both groups of schools.

The total population $(\mathrm{N})$ of private schools was 54,315 while that of public schools was $81,468 .{ }^{14}$ The standard deviation $(\sigma)$ of mean weight for age is approximately $5 \mathrm{~kg}$ for each group of schools in a previous study in Zaria. ${ }^{17}$ Since weight is more varied than height, the largest variation $(\sigma)$ from a previous study was taken to calculate the minimum sample size. Using the above formula, a minimum sample size of 100 pupils per year of age from 513 years was calculated giving a total of $900(9 \times 100)$ pupils from each group of schools and these were selected. An attrition rate of $30 \%$ was built in, which accounted for a total of 540 pupils. The minimum calculated sample size was therefore two thousand, three hundred and forty pupils $(1,800+540)$. The pupils were subsequently selected from all the classes in the study schools using the Random Number table.

Inclusion Criteria.

1. Both parents are Nigerians

2. The date, month and year of birth of the children were known.

3. Children aged between 5 and 13 years.

The exclusion criteria were any child :

1. whose parents did not give their consent.

2. whose exact date of birth was not known.

3. who is less than 5 years or more than 13 years of age.

4. with an acute illness within a period of less than two weeks before the

study.

5. with physical handicaps affecting the spine or limbs.

6. with clinical evidence of a chronic disease such as jaundice, pallor,

cyanosis and sickle cell habitus.

Official permission was obtained from the Ministry of Education, Primary Education Board, and school authorities. Ethical clearance was obtained from the Ethics committee of Ahmadu Bello University Teaching Hospital, Zaria. Informed consent was obtained from parents of the selected children, who were then given questionnaires for completion through their class teachers. The questionnaires were both in Hausa and English languages. All completed questionnaires were submitted through the class teachers to the author. Information on child's bio-data, parent's education and socioeconomic and family data were contained in the questionnaire.

\section{Equipment}

A beam balance (Mardsen weighing machines London) was used for measuring weight. The scale was calibrated to measure to the nearest 20g.Its accuracy was verified daily prior to use. Height was measured with a standard stadiometer manufactured by Holtain Ltd. Crymch, Dyfed. Its accuracy is to $1 \mathrm{~mm}$.

\section{Physical Examination and Measurements}

The physical examination of the subjects and measurements of height and weight were carried out within the school premises between 0830hrs and 
$1300 \mathrm{hrs}$ for the morning session and between 1430hrs and $1800 \mathrm{hrs}$ for the afternoon session. The study team consisted of the author and two assistants. A general physical examination was conducted by the author on selected subjects with the exclusion criteria in mind and all the measurements were also taken by the author. The techniques of measurements were as described by Tanner et al ${ }^{18}$ and Jelliffe. ${ }^{19}$ All subjects wore a standard examination cloth of known weight and only their under pants and their weight recorded to the nearest 20 grammes. Subjects stood erect, bare-footed, feet kept together on the platform of the stadiometer facing the author. The head was held in a position with the lower borders of the orbit in the same horizontal plane as the external auditory meati. The arms hung by the sides in a natural manner. The head piece was then lowered to make firm contact with the top of the child's head and at full inspiration, the height was read off to the nearest millimeter. In girls with plaited hair, allowance was made for the hair. The depth of the hair was taken with a straight rule and subtracted from the height of the child. The average hair depth as recorded by Waterlow et al ${ }^{20}$ and Umar ${ }^{17}$ was 3 millimeter for each study.

\section{Assignment of Socio-economic class}

The modified socio-economic class classification (1-V) by Oyedeji ${ }^{21}$ was used to assign a Socio-economic class to each child. The educational level and occupation of both parents were used to score each subject. The socioeconomic class was calculated from the mean of four scores (two each for the father and mother) to the nearest whole number.

\section{Data Analysis}

The program used for the computation was the Statistical Package for the Social Sciences for Personal computer (SPSS/PC+6.0)

The age intervals was grouped yearly as recommended by Waterlow et al ${ }^{20}$ (e.g. 5.0 5.9), but taken as a fraction of a year for example 5.5 for children who are at least 5 years but less than 6 years at the time of their examination as suggested by Tanner etal. ${ }^{18}$

The nutritional indices of height and weight were computed separately for age and sex for the two groups of schools.

The BMI was calculated from the formula: -

$$
\frac{\text { Weight }(\mathrm{kg})}{\operatorname{Height}^{2}(\mathrm{~m})} \quad\left(\frac{\mathrm{W}}{\mathrm{H}^{2}}\right)
$$

The BMI percentile was calculated from the mean and standard deviations with the mean corresponding to the $50^{\text {th }}$ percentile. The data were checked for skewness. They were not skewed. The graphic illustrations of the percentiles and all tabulated data were unsmoothened except otherwise stated.

\section{Statistical Comparison.}

The analysis of variance (ANOVA) method was to compare the Body Mass Indices for the two groups of schools for age and sex. This method was used because of the unequal numbers being compared. The probability value ( $p$-value) was calculated for age groups for the body mass indices of both groups of schools. The $p$-value of less than $0.05(p<0.05)$ was considered statistically significant.

\section{Results}

\section{Age and Sex Distribution of the Children}

A total of 3,802 children $(1,871$ in private and 1,931 in public schools) of ages between 5 and 13 years were studied. There was no significant difference in the sample size of both schools and sex distribution of the children in each of the groups (Table 1 below).

\section{Socio-Economic Class Distribution of the Children} One thousand four hundred and thirty children from the private schools $(76.5 \%)$ have parents from socioeconomic classes I to III, while a similar percentage $(74.2 \%)$ of children from the public schools have parents from Socio-economic classes IV and V as illustrated on the histogram in figure 1 below. The Socio-economic classes of less than $5 \%$ of the parents from both groups could not be determined.

Table I: Age and Sex Distribution of private ('privileged') and public ('less privileged') school Children

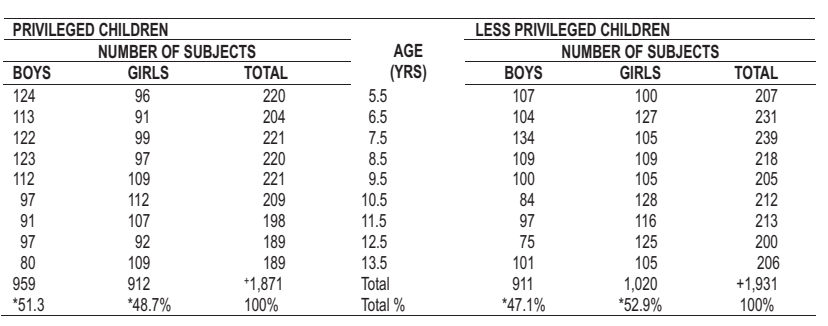

* Difference is not statistically significant $p=0.9$

Difference is not statistically significant $p=0.9$



Fig. 1: Bar chart showing the distribution of socio-economic classes of children from private and public schools. 
Table II a: Comparison of the Mean Weight/Height ${ }^{2}$ For a ge $\left(\mathrm{W} / \mathrm{H}^{2}\right)$ Indices for the 'privileged and the 'Less privileged' boys.

\begin{tabular}{|c|c|c|c|}
\hline \multirow{2}{*}{$\begin{array}{l}\text { Age } \\
\text { (yrs) }\end{array}$} & \multicolumn{3}{|c|}{ BOYS } \\
\hline & Privileged & Privileged & \\
\hline & Mean $\mathrm{W} / \mathrm{H}^{2}$ & Mean $\mathrm{W} / \mathrm{H}^{2}$ & \\
\hline 5.5 & $\begin{array}{c}13.3 \pm 1.8 \\
(124)\end{array}$ & & $\begin{array}{c}13.6 \pm 1.2 \\
(107)\end{array}$ \\
\hline 6.5 & $13.7 \pm 2.1$ & & $\begin{array}{c}13.8+1.6 \\
(104)\end{array}$ \\
\hline 7.5 & $\begin{array}{c}14.9+2.3 \\
(122)\end{array}$ & & $\begin{array}{c}14.0+3.2 \\
(134)\end{array}$ \\
\hline 8.5 & $\begin{array}{c}15.1 \pm 1.6 \\
(123)\end{array}$ & & $\begin{array}{c}14.4 \pm 3.0 \\
(109)\end{array}$ \\
\hline 9.5 & $\begin{array}{c}15.3 \pm 2.1 \\
(112)\end{array}$ & & $\begin{array}{c}14.7 \pm 1.5 \\
(100)\end{array}$ \\
\hline 10.5 & $\begin{array}{c}15.4 \pm 1.7 \\
(97)\end{array}$ & & $14.9 \pm 2.0$ \\
\hline 11.5 & $\begin{array}{c}15.7 \pm 2.3 \\
(91)\end{array}$ & & $\begin{array}{c}15.1 \pm 1.9 \\
(97)\end{array}$ \\
\hline 12.5 & $\begin{array}{c}15.8 \pm 2.1 \\
\left(9 \frac{7}{7}\right)\end{array}$ & & ${ }_{(95)}^{15.7}+2.8$ \\
\hline 13.5 & $16.5 \pm 2.2$ & & $\begin{array}{c}15.8 \pm 1.2 \\
(101)\end{array}$ \\
\hline
\end{tabular}

Figures in parenthesis are the sample sizes.

Table llb: Comparison of the Mean Weight/Height ${ }^{2}$ for age $\left(\mathrm{W} / \mathrm{H}^{2}\right)$ Indices for the 'privileged and the 'less privileged' girls.

\begin{tabular}{|c|c|c|}
\hline Age & $\begin{array}{l}\text { GIRLS } \\
\text { Privileged }\end{array}$ & \\
\hline$(y \mathbf{r s})_{5.5}$ & $\begin{array}{c}\text { Mean } \mathrm{W} / \mathrm{H}^{2} \\
13.6 \pm \frac{ \pm}{(96)}\end{array}$ & ${ }_{(100)}^{13.6}$ \\
\hline 6.5 & $13.8+2 \pm 2.4$ & ${ }_{(127)}^{14.1 \pm}$ \\
\hline 7.5 & ${ }_{(9 \overline{9} 0}^{14.3}{ }^{3.6}$ & $\underset{(105)}{14.4 \pm 1.8}$ \\
\hline 8.5 & $14.6+\frac{+}{(97)} 1.8$ & ${ }_{(109)}^{14.9}{ }^{2.7}$ \\
\hline 9.5 & ${ }_{(109)}^{14.6}{ }^{2.0}$ & ${ }_{(105)}^{14.7 \pm} 2.8$ \\
\hline 10.5 & $\underset{(112)}{15.5 \pm} 1.2$ & ${ }_{(128)}^{15.6 \pm}$ \\
\hline 11.5 & $\underset{(107)}{15.9+1.0}$ & ${ }_{(116)}^{15.7}{ }^{1.6}$ \\
\hline 12.5 & ${ }_{(92)}^{16.3}+3.2$ & ${ }_{(125)}^{15.8}+2.4$ \\
\hline 13.5 & ${ }_{(109)}^{16.8 \pm 1.5}$ & ${ }_{(105)}^{16.4} 1.9$ \\
\hline
\end{tabular}

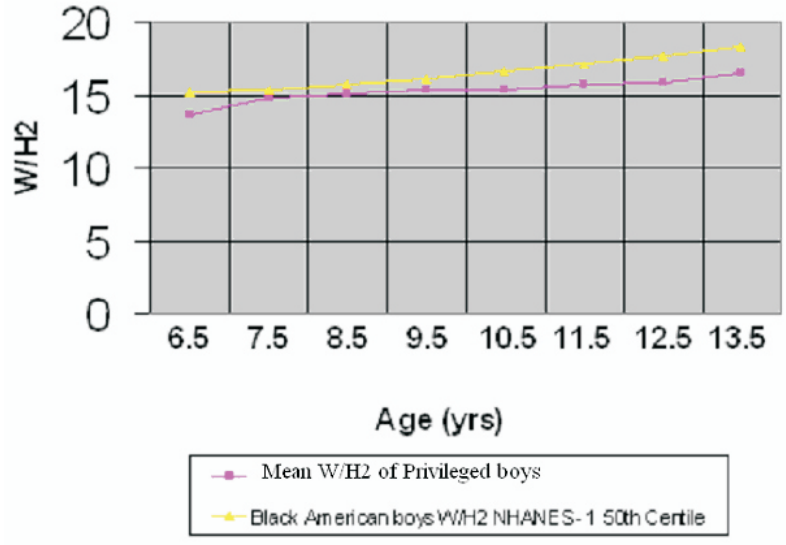

Fig 2. Comparison of Mean $\mathrm{W} / \mathrm{H}^{2}$ of Privileged boys and $50^{\text {th }}$ Centile W/ $/ \mathrm{H}^{2}$ of Black American boys
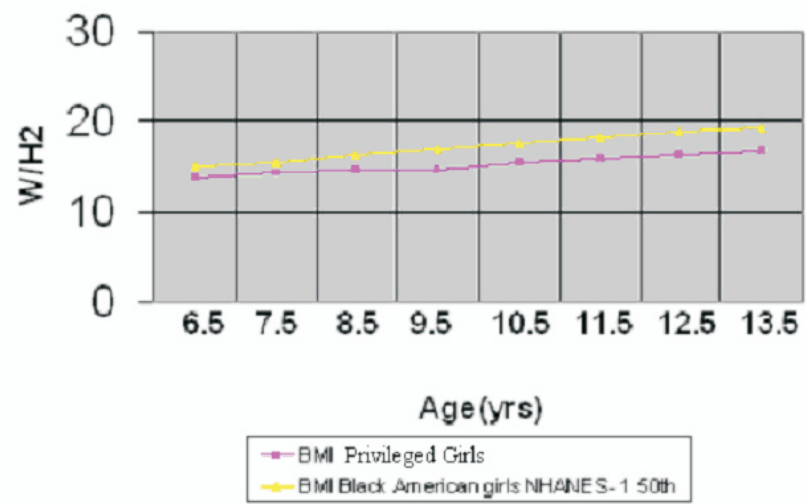

Fig 3. Comparison of Mean $\mathrm{W} / \mathrm{H}^{2}$ of Privileged girls and $50^{\text {th }}$ percentile $\mathrm{W} / \mathrm{H}^{2}$ of Black American girls

Figures in parenthesis are the sample sizes. 
Table III. Percentile Values for Weight/Height ${ }^{2}$ indices for age, for both groups of boys

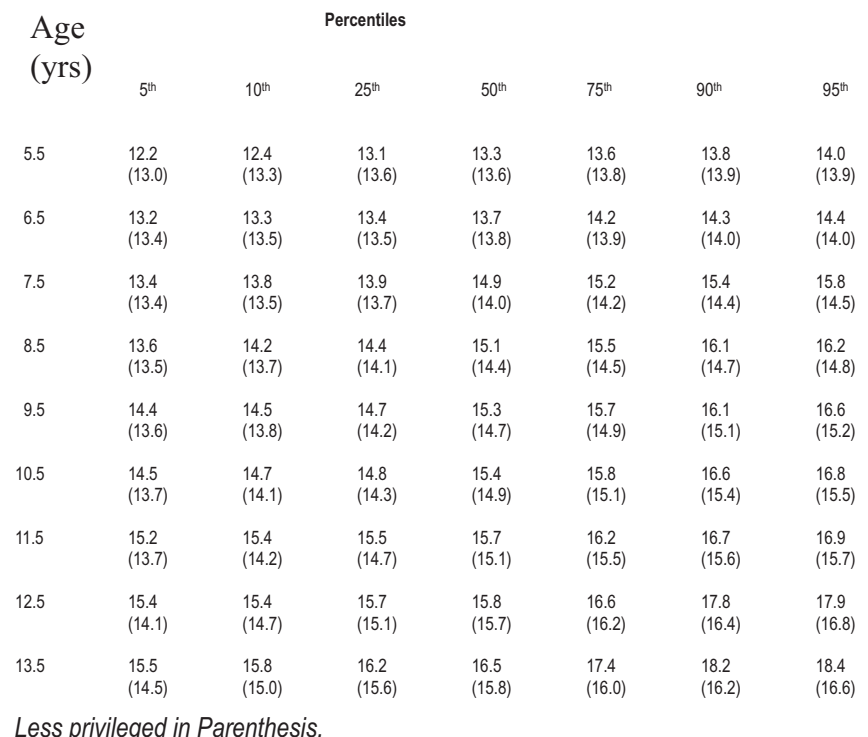

Table IV. Percentile Values for Weight/Height ${ }^{2}$ indices for age, for both groups of girls

\begin{tabular}{clllllll}
$\begin{array}{c}\text { Age } \\
\text { (yrs) }\end{array}$ & \multicolumn{7}{c}{ Percentiles } \\
& $5^{\text {th }}$ & $10^{\text {th }}$ & $25^{\text {th }}$ & 50 th & 75 th & 90 th & 95 th \\
5.5 & 13.3 & 13.4 & 13.5 & 13.6 & 14.1 & 14.6 & 14.7 \\
& $(13.0)$ & $(13.0)$ & $(13.2)$ & $(14.1)$ & $(14.2)$ & $(14.9)$ & $(14.9)$ \\
6.5 & 13.4 & 13.6 & 13.8 & 13.9 & 14.1 & 14.6 & 14.8 \\
& $(13.1)$ & $(13.2)$ & $(13.3)$ & $(14.1)$ & $(14.4)$ & $(15.0)$ & $(15.4)$ \\
7.5 & 13.5 & 14.0 & 14.2 & 14.3 & 14.4 & 14.9 & 15.8 \\
& $(13.3)$ & $(13.4)$ & $(13.9)$ & $(14.4)$ & $(14.9)$ & $(15.2)$ & $(15.6)$ \\
8.5 & 13.7 & 14.1 & 14.4 & 14.6 & 14.9 & 16.5 & 16.7 \\
& $(13.5)$ & $(13.8)$ & $(14.1)$ & $(14.9)$ & $(15.6)$ & $(16.7)$ & $(16.9)$ \\
9.5 & 14.0 & 14.3 & 14.8 & 15.5 & 17.3 & 17.4 & 18.0 \\
& $(13.7)$ & $(13.9)$ & $(14.2)$ & $(14.7)$ & $(15.2)$ & $(16.9)$ & $(17.0)$ \\
10.5 & 14.2 & 14.3 & 14.8 & 15.5 & 17.3 & 17.4 & 18.0 \\
& $(13.7)$ & $(13.9)$ & $(14.2)$ & $(15.6)$ & $(16.5)$ & $(16.9)$ & $(17.3)$ \\
11.5 & 14.7 & 14.9 & 15.7 & 15.9 & 18.8 & 19.9 & 20.0 \\
& $(13.8)$ & $(14.0)$ & $(14.8)$ & $(15.7)$ & $(16.4)$ & $(17.1)$ & $(17.3)$ \\
12.5 & 14.9 & 15.4 & 15.7 & 16.3 & 18.9 & 20.1 & 20.1 \\
& $(13.8)$ & $(14.0)$ & $(14.9)$ & $(15.8)$ & $(16.6)$ & $(17.1)$ & $(17.3)$ \\
13.5 & 15.9 & 16.5 & 16.6 & 16.8 & 19.3 & 20.1 & 20.6 \\
& $(15.1)$ & $(15.5)$ & $(16.1)$ & $(16.4)$ & $(16.9)$ & $(17.6)$ & $(17.8)$
\end{tabular}

Less privileged in Parenthesis.

Comparison of BMI Data of the 'Privileged' and 'Less Privileged' Children

The means of the weight/height ${ }^{2}$ indices of the 'privileged' and 'less privileged' boys and girls are displayed in Tables 2a\&b below. The 'privileged' and 'less privileged' boys attained the value of 15 at ages 8 and 11 years respectively, while the girls of both groups attained that value at 10 years of age. The 'privileged' boys had slightly higher mean values of BMI than their 'less privileged' counterparts, but the reverse was the case with the girls at the early ages. There was no significant statistical difference $(p=0.05)$ in the overall means of $15.1 \pm 1.7$ for the ' privileged' boys compared with the $14.7 \pm 1.2$ for the 'less privileged' boys. The difference between the mean $\mathrm{BMI}$ values of $15.1 \pm 0.5$ and $15.0 \pm 1.7$ for the 'privileged' and 'less privileged' girls respectively was also insignificant $(p=0.12)$.

The BMI values of the 'privileged' Kaduna children are lower than the American standard conducted by the National Center for Health Statistics (NCHS) ${ }^{22}$ as shown below in figure 2 .

\section{Percentiles of weight/Height ${ }^{2}$}

Displayed below in Tables 3 and 4 are the weight/height ${ }^{2}$ percentile values of the Kaduna boys and girls.

\section{Discussion}

Body Mass Index (BMI) is said to be a better index of body size than raw height or weight, and has the best correlation with body fat. ${ }^{3,1}$ The present study has shown a slightly larger mean BMI in the 'privileged' boys compared with their 'less privileged' counterparts (although statistically insignificant), while both groups of girls had similar mean BMI values. However other workers ${ }^{6,9,11}$ reported different findings. Etta and Singh ${ }^{6}$ in 1978 in Zaria, Northern Nigeria found no significant difference in BMI between the boys from the upper and lower socio-economic classes but the girls from the lower socio-economic class had higher BMI than the upper class from the age of 7.Dietary preferences and slight differences in culture between the two socioeconomic classes were considered by the authors as the reason for these differences in BMI between girls from the lower and higher socio- economic classes. However, in Brazil, ${ }^{9}$ the urban adolescents had higher $\mathrm{BMI}$ values than those living in the rural areas. The authors attributed this to socio-economic factors in favor of the urban dwellers while Lazarus et al ${ }^{11}$ in 1996 reported in Australia that the BMI as a screening index was more sensitive among girls than boys although the differences were insignificant. The greater deficit in weight than in height among the 'less privileged' boys resulted in their lower mean BMI observed in this study. However, similar deficits in weight as well as height of the 'less privileged' girls accounted for the comparable mean BMI with the 'privileged' girls.

In both groups of this study, the girls had higher BMI than the boys. This finding is probably due to genetic differences between the sexes since BMI correlates with body fat which is known to be higher in girls especially around puberty than in boys. ${ }^{2}$ 
The 'privileged' boys of this study had a higher BMI than the Zaria ${ }^{6}$ upper class boys only at the earlier ages (5$9 y e a r s)$ beyond which the latter group had higher values. However the girls in both groups have similar BMI. The reason for these findings may be a decline in socioeconomic factors over the years. This is contrary to the increasing secular trends in BMI reported among 6 year old children in Chile over a 15 year preiod. ${ }^{10}$ The authors said it is consistent with changes in energy density of the diet, increased physical inactivity and lower prevalence of infection.

The 'privileged' and the 'less privileged' boys attained the normal BMI range of 15 to 18 determined in Zaria by Etta and $\operatorname{Singh}^{6}$ at 8 and 11 years respectively, while the girls of both groups did at the age of 10 years each. Conversely, in Calabar, South Eastern Nigeria the BMI of 15-18 was attained by both boys and girls at later ages of 12 and 16 years respectively. ${ }^{8}$ Large variation in sample sizes at different ages was the reason given by the authors for this observation. Nutritional factors may be responsible for the delay in 'the less privileged' boys attaining the above values when compared with their 'privileged' counterparts in this study

The BMI of the Black American children ${ }^{22}$ in North America sampled from all socio- economic classes were consistently higher than the children in this present study. In Brazil, ${ }^{6}$ the BMl of black children (both sexes) were

\section{References}

1. Rao VK, Singh D. An Evaluation of the relationship between nutritional status and anthropometric measurements. Am J Clin Nutr 1970; 23:83-93.

2. Lee J, Kolonel LN, Hinds MW. Relative merits of old and new indices of body mass: a commentary. Am J Clin Nutr 1982; 36:727-28.

3. Ivanovic D, Olivares M, Casreo C, Ivanovic R. Nutritional Status of school children in poverty conditions from urban and rural areas. Metropolitan region. Chile. 1986-1987. Rev Med Chil 1995; 123:509-25.

4. Roland-Cachera MF, Sempe`M, Guilloud-Bataille M, Patois E, Pequignot- Guggenbul F, Fautrad V. Adiposity indices in children. Am J Clin Nutr. 1982;36: 178-184.

5. Cole TJ, Freeman JV, Preece MA. Body mass index reference curves for the UK,1990. Arch Dis Child. 1995;73:25-29.

6. Etta KM, Singh A. Towards the establishment of norms: (2) skinfolds and subcutaneous fat for Africans of two socioeconomic classes. Trop Paediatr Environ child Hlth 1979;25:119-126.

7. Emodi KJ, Kaine MN. Weights, heights and Quetelet's indices of children with sickle-cell anaemia (sicklers). Nig J Paediatr 1996 23:37-41. however lower than the Whites of the same age. Increased physical activities, dietary or climatic factors may have affected the Kaduna children in their environment, but not socio- economic factors since the Black American children ${ }^{22}$ were sampled from all the different socio-economic classes.

The BMI percentiles for age and sex for this study are lower than the American standard. ${ }^{22}$ The widely recommended use of the American $85^{\text {th }}$ or $95^{\text {th }}$ percentiles of BMI as cut off points for children is arbitrary, because of the wide variation of BMI in ,different populations. ${ }^{23}$ BMI percentile values from different populations are needed to standardize standards for children.

In conclusion, there was no statistical significant difference between the BMI of the 'privileged' and the 'less privileged' groups of children. The BMI of Kaduna children were lower than those of black American children. ${ }^{22}$

As contribution, this study provides mean BMl values for age and sex for children from different socio- economic classes as well as percentile values for Nigerian children.

\section{Recommendation}

A nation wide study of BMI should be carried out to establish national reference values.

8. Ansa VO, Odigwe CO, Anah MU. Profile of body mass index and obesity in Nigerian children and adolescents. Niger J Med 2001;10(2):78-80.

9. Sichieri R, Recine E, Everhart JE. Growth and body mas index of Brazilians ages 9 through 17years Obes Res 1995; 3:117-121

10. Kain J, Uauy R, Lera L, Taibo M, Albala C. Trends in height and BMI of 6 -year old children during the nutrition transition in Chile. Obes Res 2005;13(12):2178-

2186.

11. Lazarus R, Baur I, Webb K, Blyth F. Body mass index in screening for adiposity in children and adolescents: Systematic evaluation using receiver operating character curves. Am J Clin Nutr 1996; 63:500-6.

12. Population census 1963. Projections 1984 1990. Ministry of Finance and Economic Planning, Kaduna Statistics Division, Kaduna.

13. Baigaya HN. Location and distribution of health facilities in Kaduna metropolis. Department of Urban and Regional Planning, School of Environmental Design, Kaduna Polytechnic project, August 1990; 42-56.

14. Kaduna State primary Education Board, Kaduna 1996. Unpublished information.

15. WHO. Measuring change in nutritional status. Guidelines for assessing the nutritional impact of supplementary feeding 
programmes for vulnerable groups. WHO. Geneva 1983; 48 55.

16. Singha F. An introductory textbook on Biostatistics, Ahmadu Bello University Press, Zaria 1992: 189-204.

17. Umar BA. Heights and Weights of School Children in Zaria Nigeria. Part II dissertation to National Post-Graduate Medical College of Nigeria 1986:31-32.

18. Tanner JM, Whitehouse RH, Takaishi M. Standards from birth to maturity for height, weight, height velocity, and weight velocity of British Children, 1965.

Part 1. Arch Dis Child 1966; 41:454-71.

19. Jelliffe DB. The Assessment of nutritional status of the community. Geneva,

World Health Organisation WHO Monog 1966; 53:51-55, 78, 125, 227-229.
20 Waterlow JC, Buzina R, Keller Water. The presentation and use of height and weight data for comparing the nutritional status of groups of children under the age of 10 years. Bull Wld HIth Org 1977:55:469-98.

21. Oyedeji GA. Socio-economic and cultural backgrounds of hospitalized children in llesha. Nig J Paediatr 1985; 12:11117.

22. Cronk CE, Roche AF. Race and Sex-specific reference data for triceps and subscapular skinfolds and weight stature. Am J Clin Nutr 1982; 35:347-54.

23. Cole TJ, Bellizi MC, Flegal KM, Dietz WH. Esablishing a standard definition for child overweight and obesity worldwide: International survey. BMJ 2000; 320(7244):1240-1250. 